\title{
Left ventricular mechanical dyssynchrony for CAD diagnosis: Does it have incremental clinical values?
}

\author{
Zhixin Jiang, MD, a and Weihua Zhou, PhD $^{\mathrm{b}}$ \\ a Department of Cardiology, The First Affiliated Hospital of Nanjing Medical University, Nanjing, \\ Jiangsu, China \\ b School of Computing, University of Southern Mississippi, Long Beach, MS
}

Received Aug 31, 2018; accepted Aug 31, 2018

doi:10.1007/s12350-018-1440-3

\section{See related article, pp. 241-250}

Gated single-photon emission computed tomography (SPECT) myocardial perfusion imaging (MPI) has been widely practiced to assess left ventricular (LV) function after stress and at rest, which has in turn improved the diagnosis of coronary artery disease (CAD). The visualization of wall motion and thickening has greatly improved the identification of attenuation artefacts $^{1,2}$ and allows the recognition of stress-induced abnormalities in the case of post-ischemic stunning which helps with multi-vessel CAD detection. ${ }^{3}$

Recently, the phase analysis technique has become a major innovation in nuclear cardiology and greatly boosted the clinical values of MPI scans. It measures the LV mechanical dyssynchrony (LVMD) and wall thickening from the regional LV count changes throughout the cardiac cycle. ${ }^{4,5}$ Previous studies identified LVMD as an independent predictor for a favorable response to cardiac resynchronization therapy ${ }^{6}$ and for all-cause death in patients with dilated cardiomyopathy and narrow QRS. ${ }^{7}$

LVMD has also demonstrated its clinical values in CAD diagnosis. As reported by Uebleis et al., ${ }^{8}$ the occurrence of LVMD is mainly influenced by reduced myocardial contractility as expressed by the summed thickening score (STS). In a recent study, STS and the

Reprint requests: Zhixin Jiang, MD, Department of Cardiology, The First Affiliated Hospital of Nanjing Medical University, Nanjing, Jiangsu 210029, China; zhixin_jiang@njmu.edu.cn; Weihua Zhou, $\mathrm{PhD}$, School of Computing, University of Southern Mississippi, Long Beach, MS 39560; weihua.zhou@usm.edu

J Nucl Cardiol 2020;27:251-3.

$1071-3581 / \$ 34.00$

Copyright (C) 2018 American Society of Nuclear Cardiology. proportion of segments with reduced wall thickening in segments with normal perfusion were the independent risk factors of $\mathrm{LV}$ remodeling in myocardial infarction patients. ${ }^{9}$ Thus it is not a surprise to see that LVMD is related with stress-induced myocardial ischemia. ${ }^{10-13}$ Chen et al. ${ }^{11}$ firstly demonstrated different LVMD changes in ischemic, infarcted, and normal myocardium using gated thallium-201 SPECT MPI, which was acquired at 5-10 minutes after stress. Other researchers have also found the evidence of stress-induced LVMD when acquisitions were performed earlier than one hour post-stress with technetium-99m sestamibi. ${ }^{14-16}$ Our research showed that, in patients with moderate-to-severe myocardial ischemia, LVMD changes were also related to myocardial stunning even when the acquisition was 60 minutes after stress. ${ }^{17}$

Furthermore, the direct comparison with coronary angiography has suggested that LVMD can help with multi-vessel CAD detection. Hida et al. ${ }^{14}$ reported that in the detection of 128 patients with multi-vessel CAD, a summed stress score (SSS) of $\geq 9$ showed a sensitivity of $84 \%$ and a specificity of $53 \%$, while after exercise an increase in phase standard deviation (PSD) of $\geq 4.4^{\circ}$ and phase bandwidth (PBW) of $\geq 14^{\circ}$ had sensitivities of $74 \%$ and $68 \%$, and specificities of $84 \%$ and $91 \%$, respectively. Huang et al. ${ }^{18}$ demonstrated that patients with severe multi-vessel CAD had more significantly global and territorial LVMD. Gimelli et al. ${ }^{19}$ reported that in patients with suspected or known CAD, the presence and severity of LVMD was correlated with the extent of $\mathrm{CAD}$, and that it was significantly more prevalent in patients with multi-vessel CAD.

In the current issue of the journal, Lin et al. ${ }^{20}$ investigated the diagnosis value of LVMD in patients with less severe CAD (coronary artery stenosis $\geq 50 \%$ ). A total of 476 patients without known CAD who underwent dipyridamole-gated SPECT MPI and 
coronary angiography within 6 months were enrolled. Depending on the duration and severity of ischemia, myocardial stunning lasts from minutes to days. Thus immediate acquisition after stress is better for the detection of this phenomenon. ${ }^{21}$ In this study, with thallium-201 and cadmium-zinc-telluride detectors, the acquisition time was possible during 5 minutes after radiotracer injection. They concluded that perfusion abnormalities like SSS and summed difference score (SDS) were still the best diagnostic tools in detecting CAD, although less LVMD was observed post-stress in the CAD group compared to the non-CAD group. Regarding this study, we have following comments:

Firstly, it is a good attempt to use $50 \%$ as a definition for CAD, which tested the sensitivity of LVMD for CAD diagnosis. In prior studies, coronary artery stenosis of $70-75 \%$ was mostly used ${ }^{14,18,19}$ and myocardial ischemia is usually related with more severe coronary stenosis ( $\geq 70 \%)$. The current study found that only SDS, age, hypertension, and smoking were related with CAD. Though the results were negative, it still contributes to the knowledge that LVMD from gated SPECT MPI have limitations for the diagnosis of mild CAD.

Secondly, both global and regional LV function parameters have been used to detect myocardial stunning, such as reduced LV ejection fraction, ${ }^{21}$ enlarged end diastolic volume or end systolic volume, ${ }^{14}$ and decreased wall motion ${ }^{22-24}$ or wall thickening. ${ }^{24}$ Whether the addition of LVMD and wall thickening can yield increased diagnostic value beyond these variables, especially STS, is unknown. Hida et al. ${ }^{14}$ found that the combination of post-stress increases in PSD, PBW, transient ischemic dilation (TID) ratio, and SSS best identified multi-vessel CAD (sensitivity $77 \%$, specificity $88 \%$ ), compared with TID ratio and SSS only (sensitivity $70 \%$, specificity $76 \%$ ). In another study, ${ }^{25}$ patients with systolic dysfunction were evaluated. SDS, SSS, and changes in PSD and PBW with stress were greater in 26 patients with CAD than those in 15 patients without CAD. In the multivariate analysis, a PSD of $>14^{\circ}$ and a SSS of $>17$ best differentiated LV dysfunction of ischemic and non-ischemic etiologies, with a sensitivity of $89 \%$ and a specificity of $87 \%$, compared with SDS only (sensitivity, $46 \%$; specificity, $87 \%$ ).

Last, it is noteworthy that a total of 476 patients and over 27 clinical variables were included in the patient baseline, univariate and multivariate, and subgroup analysis. Variable interaction may be an issue in the statistical analysis, for example, it has been demonstrated by Ludwig et al. that PSD may be spuriously increased by scar. ${ }^{26}$ These may challenge the traditional linear analysis. Algorithms for the non-linear model with a big number of inter-correlated variables may further improve the accuracy of the prediction. Machine learning may be a good choice. In a recent multi-center study with 10,030 patients with suspected CAD, Motwani et al. used machine learning to predict 5-year allcause mortality and achieved an AUC of $0.79 .{ }^{27}$ In their method, the information gain algorithm was employed to select important variables from 25 clinical and 44 coronary CTA parameters, and the LogitBoost Algorithm was employed to build the prediction model.

\section{Disclosure}

The authors have nothing to disclose.

\section{References}

1. Chua T, Kiat H, Germano G, Maurer G, van Train K, Friedman J, et al Gated technetium-99m sestamibi for simultaneous assessment of stress myocardial perfusion, postexercise regional ventricular function and myocardial viability. Correlation with echocardiography and rest thallium-201 scintigraphy. J Am Coll Cardiol. 1994;23:1107-14

2. Nichols K, DePuey EG, Krasnow N, Lefkowitz D, Rozanski A. Reliability of enhanced gated SPECT in assessing wall motion of severely hypoperfused myocardium: echocardiographic validation. J Nucl Cardiol. 1998;5:387-94.

3. Sciagra R. The expanding role of left ventricular functional assessment using gated myocardial perfusion SPECT: the supporting actor is stealing the scene. Eur J Nucl Med Mol Imaging. 2007;34:1107-22

4. Chen J, Garcia EV, Folks RD, Cooke CD, Faber TL, Tauxe EL, et al Onset of left ventricular mechanical contraction as determined by phase analysis of ECG-gated myocardial perfusion SPECT imaging: development of a diagnostic tool for assessment of cardiac mechanical dyssynchrony. J Nucl Cardiol. 2005;12:68795.

5. Zhou W, Garcia EV. Nuclear image-guided approaches for cardiac resynchronization therapy (CRT). Curr Cardiol Rep. 2016;18:7.

6. Henneman MM, Chen J, Dibbets-Schneider P, Stokkel MP, Bleeker GB, Ypenburg C, et al Can LV dyssynchrony as assessed with phase analysis on gated myocardial perfusion SPECT predict response to CRT? J Nucl Med. 2007;48:1104-11.

7. Kano N, Okumura T, Isobe S, Sawamura A, Watanabe N, Fukaya $\mathrm{K}$, et al Left ventricular phase entropy: Novel prognostic predictor in patients with dilated cardiomyopathy and narrow QRS. J Nucl Cardiol. 2017. https://doi.org/10.1007/s12350-017-0807-1.

8. Uebleis C, Hoyer X, Van Kriekinge SD, Schuessler F, Laubender $\mathrm{RP}$, Becker A, et al Association between left ventricular mechanical dyssynchrony with myocardial perfusion and functional parameters in patients with left bundle branch block. J Nucl Cardiol. 2013;20:253-61.

9. Yang W, Zhang F, Tang H, Shao X, Wang J, Wang X, et al Summed thickening score by myocardial perfusion imaging: A risk factor of left ventricular remodeling in patients with myocardial infarction. J Nucl Cardiol. 2018;25:742-53.

10. Aljaroudi W, Koneru J, Heo J, Iskandrian AE. Impact of ischemia on left ventricular dyssynchrony by phase analysis of gated single photon emission computed tomography myocardial perfusion imaging. J Nucl Cardiol. 2011;18:36-42.

11. Chen CC, Shen TY, Chang MC, Hung GU, Chen WC, Kao CH, et al Stress-induced myocardial ischemia is associated with early 
post-stress left ventricular mechanical dyssynchrony as assessed by phase analysis of $201 \mathrm{Tl}$ gated SPECT myocardial perfusion imaging. Eur J Nucl Med Mol Imaging. 2012;39:1904-9.

12. Singh H, Patel CD, Sharma P, Naik N, Singh S, Narang R. Does perfusion pattern influence stress-induced changes in left ventricular mechanical dyssynchrony on thallium-201-gated SPECT myocardial perfusion imaging? J Nucl Cardiol. 2015;22:36-43.

13. Zhou Y, Li D, Feng J, Yuan D, Patel Z, Cao K, et al Left ventricular dyssynchrony parameters measured by phase analysis of post-stress and resting gated SPECT myocardial perfusion imaging. World J Nucl Med. 2013;12:3-7.

14. Hida S, Chikamori T, Tanaka H, Igarashi Y, Shiba C, Usui Y, et al Diagnostic value of left ventricular dyssynchrony after exercise and at rest in the detection of multivessel coronary artery disease on single-photon emission computed tomography. Circ J. 2012;76:1942-52.

15. Karacalioglu AO, Balta S, Emer O, Demirkol S, Celik T, Ozguven M. Phase analysis in patients with reversible perfusion defects and normal coronary arteries at angiography. Ann Nucl Med. 2013;27:416-22.

16. Peix A, Cabrera LO, Padron K, Rodriguez L, Fernandez J, Lopez $\mathrm{G}$, et al Association between non-perfusion parameters and presence of ischemia in gated-SPECT myocardial perfusion imaging studies. J Nucl Cardiol. 2016;25:609-15.

17. Jiang Z, Tang H, Shi J, Zhou Y, Wang C, Li D, et al Myocardial stunning-induced left ventricular dyssynchrony on gated singlephoton emission computed tomography myocardial perfusion imaging. Nucl Med Commun. 2018;39:725-31.

18. Huang WS, Huang CH, Lee CL, Chen CP, Hung GU, Chen J. Relation of early post-stress left ventricular dyssynchrony and the extent of angiographic coronary artery disease. J Nucl Cardiol. 2014;21:1048-56.

19. Gimelli A, Liga R, Giorgetti A, Favilli B, Pasanisi EM, Marzullo P. Determinants of left ventricular mechanical dyssynchrony in patients submitted to myocardial perfusion imaging: A cardiac CZT study. J Nucl Cardiol. 2016;23:728-36.
20. Lin WL, Wang SY, Shiau YC, Wu YW. The clinical usefulness of phase analysis in detecting coronary artery disease using dipyridamole thallium-201-gated myocardial perfusion imaging with a cadmium-zinc-telluride camera. J Nucl Cardiol. 2018. https://doi. org/10.1007/s12350-018-1417-2.

21. Mut F, Giubbini R, Vitola J, Lusa L, Sobic-Saranovic D, Peix A, et al Detection of post-exercise stunning by early gated SPECT myocardial perfusion imaging: results from the IAEA multi-center study. J Nucl Cardiol. 2014;21:1168-76.

22. Ward RP, Gundeck EL, Lang RM, Spencer KT, Williams KA. Overestimation of postischemic myocardial stunning on gated SPECT imaging: correlation with echocardiography. J Nucl Cardiol. 2006;13:514-20.

23. Hacker M, Rieber J, Schmid R, Lafougere C, Tausig A, Theisen K, et al Comparison of Tc-99m sestamibi SPECT with fractional flow reserve in patients with intermediate coronary artery stenoses. J Nucl Cardiol. 2005;12:645-54.

24. Santiago JF, Heiba SI, Jana S, Mirzaitehrane M, Dede F, AbdelDayem HM. Transient ischemic stunning of the myocardium in stress thallium-201 gated SPET myocardial perfusion imaging: segmental analysis of myocardial perfusion, wall motion and wall thickening changes. Eur J Nucl Med Mol Imaging. 2002;29:97983.

25. Igarashi Y, Chikamori T, Hida S, Tanaka H, Shiba C, Usui Y, et al Usefulness of phase analysis to differentiate ischemic and nonischemic etiologies of left ventricular systolic dysfunction in patients with heart failure. Circ J. 2014;78:141-50.

26. Ludwig DR, Friehling M, Schelbert EB, Schwartzman D. Impact of scar on SPECT assay of left ventricular contraction dyssynchrony. Eur J Nucl Med Mol Imaging. 2014;41:529-35.

27. Motwani M, Dey D, Berman DS, Germano G, Achenbach S, AlMallah $\mathrm{MH}$, et al Machine learning for prediction of all-cause mortality in patients with suspected coronary artery disease: a 5year multicentre prospective registry analysis. Eur Heart J. 2017;38:500-7. 